\title{
Prediction of exergetic efficiency of arc shaped wire roughened solar air heater using ANN model
}

\author{
Harish K. Ghritlahre*, Radha K. Prasad \\ Department of Mechanical Engineering, National Institute of Technology, Jamshedpur, Jharkhand 831014, India
}

Corresponding Author Email: harish.ghritlahre@gmail.com

https://doi.org/10.18280/ijht.360343

Received: 9 March 2018

Accepted: 29 May 2018

\section{Keywords:}

solar air heater, artificial neural network, exergy efficiency, learning algorithm, multi-layer perceptron

\begin{abstract}
In present work, Artificial Neural Network (ANN) model has been structured to predict the exergetic efficiency of roughened solar air heater. Arc shaped wire rib roughened absorber plate with relative roughness pitch $(P / e)=10$, relative roughness height $(e / D)=0.0395$ and angle of attack $(\alpha)=60^{\circ}$ is used in the experiments. Experiments were conducted at Jamshedpur (India) under the local weather conditions for 7 days between 09:00 and 16:00 $h$ in the month of February. Total 105 data samples have been collected from the experiments. By the use of experimental data and calculated values of exergy efficiency were used to develop ANN model. The MLP model has been developed with eight parameters in input layer and one parameter in output layer. Levenberg-Marquardt (LM) learning algorithm has been used to training an ANN model. For optimal topology, 10-16 neurons were used to train the network and found that 14 numbers of neurons with single hidden layer is optimal on the basis of statistical error analysis. The values of $\mathrm{R}^{2}$ for predicted exergetic efficiency is 0.99583 which shows that predicted values are very close to experimental data. The statistical analysis also show that the value of RMSE and COV were 0.021747 and 1.63766 respectively, which are very low as required for accurate prediction. The statistical results show that the proposed MLP model successfully predicts the exergetic performance of roughened solar air heater.
\end{abstract}

\section{INTRODUCTION}

A solar air heater $(\mathrm{SAH})$ is a device which absorbs solar radiations and transfers the absorbed thermal energy to the flowing fluid (air) and this heated air is used various applications such as for space heating in commercial and residential buildings, crop drying, timber seasoning and low temperature heating applications. The thermal efficiency of a solar air heater is low due to small heat capacity and low thermal conductivity of flowing air. The convective heat transfer coefficient between absorber plate and the air is low, and hence the major issue is to increase the value of heat transfer coefficient [1-2].

Several types of methods have been used to improve the performance of a solar air heater such as using packed beds, fins and artificial roughness elements. One of the better methods of increasing the performance of a solar air heater is to provide artificial roughness on the underside of the absorber plate. By the use of roughness turbulence is created near the absorber plate surface which increases the heat transfer coefficient. Many researchers [3-6] have studied on the performance enhancement of solar air heaters by using artificial roughness on absorber plate.

In the present study, concept of exergy analyses has been used for evaluating the performances of roughened absorber plate SAH by ANN modeling. The quantitative energy analysis of any system is based on first law of thermodynamics, whereas the qualitative analysis is based on second law of thermodynamics [7]. In recent years many researchers have carried out energy and exergy analyses of solar thermal systems. Alta et al. [8] conducted experiments to investigate the energy and exergy analysis of three different types of
SAHs. Lalji et al. [9] conducted experiments on packed bed $\mathrm{SAH}$ for various mass flow rates of air and for different porosities of packing material and evaluated exergy of the system. Sahu and Prasad [10] analytically investigated the exergy analysis of arc shaped wire rib roughened solar air collector.

The experimental and analytical study followed by the computational techniques requires a lot of time to arrive at an accurate result due to extensive computer codes for the solution of complex differential equations [11]. The use of Artificial Neural Networks (ANN), on the other hand, saves time and also provides key information patterns in a multidimensional information domain and, therefore, this technique has been becoming increasingly popular in Science and Engineering sectors. In recent years, many researchers have used ANN in solar collector systems [12-26]. Caner et al. [15], Benli [16], and Ghritlahre and Prasad [17-26] specially applied ANN model to predict the performance of different types of SAH.

The exergetic performance of solar air heaters is evaluated by conducting actual experiments and/or by developing mathematical models. In case of experimental analysis, the experimentation is time consuming and costlier. On the other hand, the analytical approach requires use of numerical method and huge programming codes for solution of the complex governing equations. These difficulties can be avoided by using ANN technique. It is found from the literature that the ANN technique has been mostly used for thermal performance prediction of solar air heaters, but no work has been carried out on exergetic performance prediction of SAH using ANN model. In view of this, MLP model has been used in the present study to estimate the exergy efficiency 
of solar air heaters. This model has been developed by using measured experimental data and the calculated values of exergy efficiency. Total 105 sets of experimental data have been collected using arc shape wire rib roughened absorber plate. The ANN model consists of eight parameters in input layer and one parameter in output layer. 10-16 neurons have been used in hidden layer to obtain the optimal network for prediction of output data and it has been found that 8-14-1 neurons with LM learning algorithm obtained as an optimal model. Statistical error analysis has been performed for predicted values of exergy efficiency [28].

\section{EXPERIMENTAL SYSTEM DEVELOPEMENT AND DATA COLLECTION}

The SAH experimental setup duct designed with length 230 $\mathrm{cm}$, width $33 \mathrm{~cm}$ and height $3.5 \mathrm{~cm}$. The test section is a rectangular duct having arc shape wire- roughened absorber plate. It consists of a $4 \mathrm{~mm}$ thick glass cover at its top.
Fig .1 shows the structure of the test section. The absorber plate is made of $1 \mathrm{~mm}$ thick Galvanized iron (GI) sheet provided with arc shape wire and its specifications as given in Table. 1. A configuration of wire-roughness used on the absorber plate has been shown in Fig. 2 whereas a photographic view of the same has been given in Fig.3. The Test section is connected with 2.5 inch diameter GI pipe provided with an Orifice meter to measure mass flow rate of air through the SAH duct. The pressure drop was measured with the help of a U-tube Manometer fitted across the orifice plate. The mass flow rate was varied from 0.0067 to 0.0227 $\mathrm{kg} / \mathrm{sec}$. A $5 \mathrm{HP} / 3$-phase suction blower was used to carry air through the SAH duct. The intensity of solar radiation was measured with digital pyranometer (Fig 4). For measuring the temperature at various sections of absorber plate and air temperatures at inlet and outlet, digital thermometers were used. The experiments were conducted in clear sky at Jamshedpur (India) in the month of February, 2017 and data were taken from 09:00 to 16:00 hr. Total 105 sets of experimental data were collected from experiments with various mass flow rate of air.

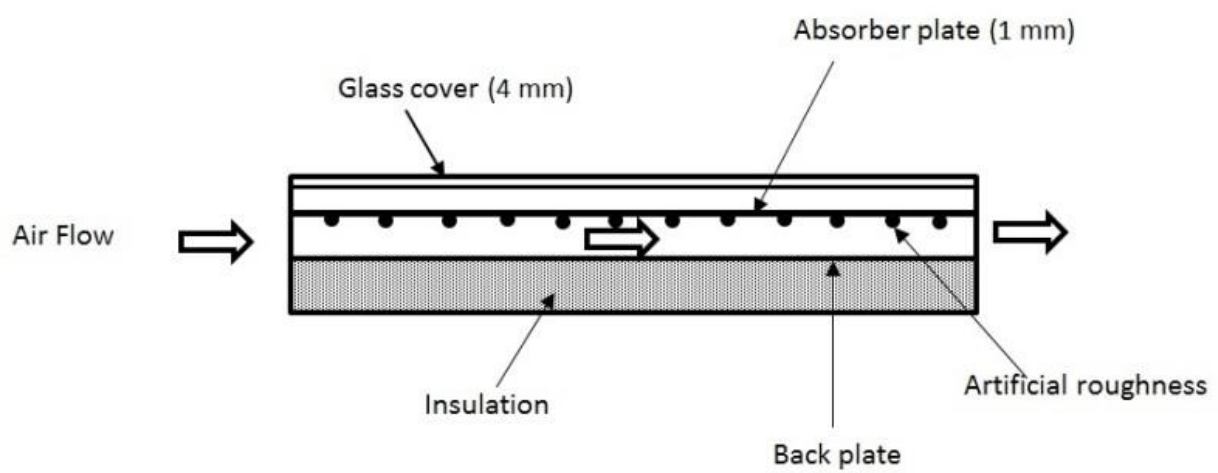

Figure 1. Test section diagram

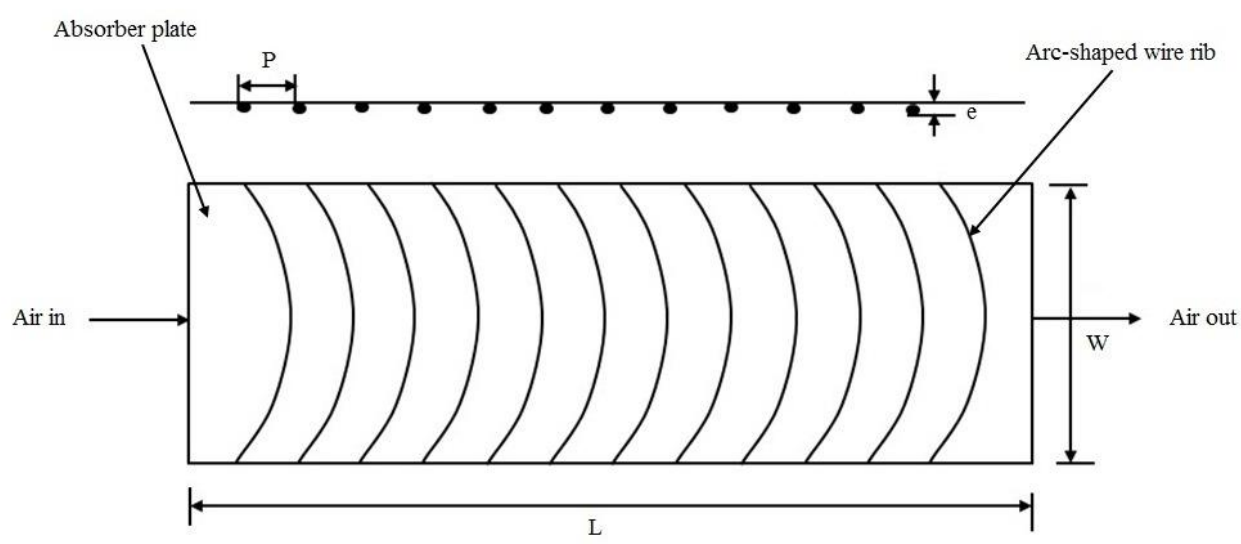

Figure 2. Arc shape wire roughened absorber plate

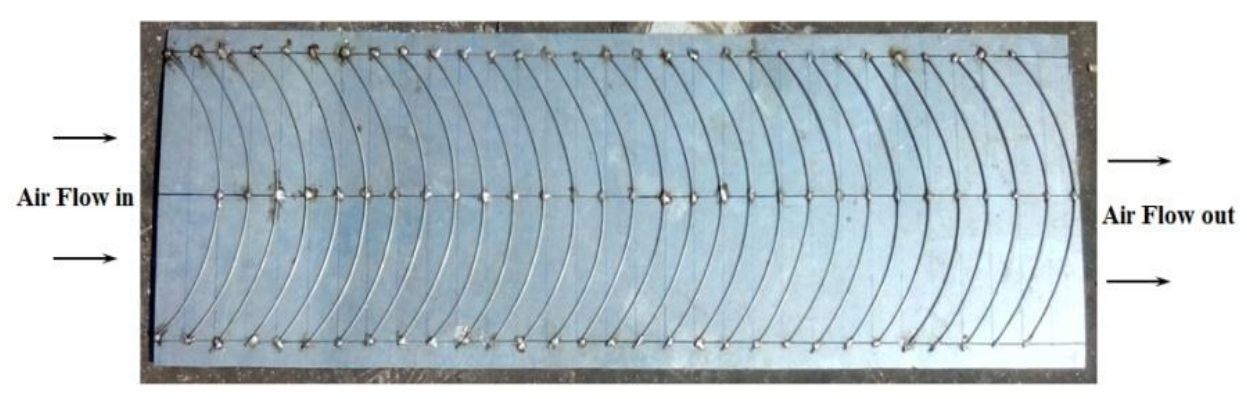

Figure 3. Photographic view of absorber plate 


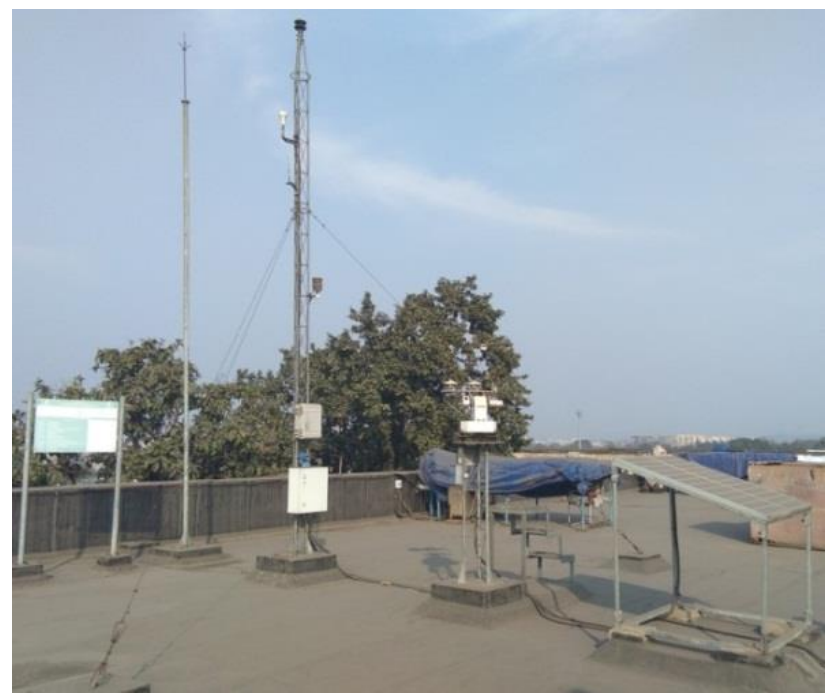

Figure 4. Photographic view of digital pyranometer

Table 1. Specification of arc shape wire rib roughness

\begin{tabular}{|c|c|}
\hline Roughness parameter & Value \\
\hline Relative roughness pitch $(P / e)$ & 10 \\
\hline Relative roughness height $(e / D)$ & 0.0395 \\
\hline Roughness height $(e), \mathrm{mm}$ & 2.5 \\
\hline Angle of attack $(\alpha)$, degree & $60^{\circ}$ \\
\hline
\end{tabular}

\section{ANALYSIS OF EXERGY}

The analysis of exergy is most useful concept for optimal utilization of energy. This analysis is used to make strategies for designing and operation of industrial processes. The exergetic efficiency is defined as the ratio of exergy gained from the system to exergy input to the system [7, 22, 27].

Following assumptions have been undertaken in the present analysis:

1. The system works under steady state condition.

2. Kinetic energy and potential energy are negligible.

3. Chemical and nuclear reactions are not possible to occur in operation of the system.

4. The air specific heat is constant and it is considered as an ideal fluid.

5. The direction of heat transfer to the system and work transfers from the system are positive

In general, energy and exergy balance equations in rate form with negligible kinetic and potential energies can be written as [7-8 and 20]:

$\sum \dot{E}_{i}=\sum \dot{E}_{o}$

$\sum E x_{i}-\sum E x_{o}=\sum E x_{d}$

or

$E x_{\text {heat }}-E x_{\text {work }}+E x_{\text {mass, in }}-E x_{\text {mass out }}$
Eq. (3) can also be expressed in the form of general exergy equation as given below:

$\sum\left(1-\frac{T_{a}}{T_{s}}\right) \dot{Q_{c}}-\dot{W}+\sum \dot{m}_{i} \psi_{i}-\sum \dot{m}_{o} \psi_{o}=\sum \dot{E} x_{\text {dest }}$

where,

$\psi_{i}=\left(h_{i}-h_{a}\right)-T_{a}\left(\mathrm{~s}_{i}-s_{a}\right)$

$\psi_{o}=\left(h_{o}-h_{a}\right)-T_{a}\left(\mathrm{~s}_{o}-s_{a}\right)$

From Eq.(4),(5) and (6), the expression:

$\left(1-\frac{T_{a}}{T_{s}}\right) \dot{Q_{c}}-\dot{m}\left[\left(h_{o}-h_{i}\right)-T_{a}\left(\mathrm{~s}_{o}-s_{i}\right)\right]=\sum \dot{E} x_{\text {dest }}$

where

$Q_{c}=I A_{c}$

The change in the enthalpy and the entropy of the air

$\Delta h_{a i r}=h_{o}-h_{i}=C_{p f}\left(T_{f o}-T_{f i}\right)$

$\Delta s_{a i r}=s_{o}-s_{i}=C_{p f} \ln \frac{T_{f o}}{T_{f i}}-R_{a} \ln \frac{P_{o}}{P_{i}}$

$=E x_{\text {dest }}$ 
From Eq.(7), (8), (9) and (10) the following expression can be obtained:

$$
\begin{aligned}
& \left(1-\frac{T_{a}}{T_{s}}\right) I A_{c}-\dot{m} C_{p f}\left(T_{f o}-T_{f i}\right)+ \\
& \dot{m} T_{a}\left(C_{p f} \ln \frac{T_{f o}}{T_{f i}}-R_{a} \ln \frac{P_{o}}{P_{i}}\right)=\sum \dot{E} x_{\text {dest }}
\end{aligned}
$$

The irreversibility/exergy destruction may be expressed as follows:

$$
\dot{E} x_{d e s t}=T_{a} \cdot \dot{S}_{g e n}
$$

The exergy efficiency of SAH can be formulated by the ratio of net exergy output of the system to exergy input of the system $[8,22]$.

$$
\eta_{I I}=\frac{\dot{E} x_{o}}{\dot{E} x_{i}}=\frac{\dot{m}\left[\left(h_{o}-h_{i}\right)-T_{a}\left(\mathrm{~s}_{o}-s_{i}\right)\right]}{\left(1-\frac{T_{a}}{T_{S}}\right) I A_{c}}
$$

\section{ARTIFICIAL NEURAL NETWORK TECHNIQUE}

$(\mathbf{A N N})$

Artificial Neural Network (ANN) is a complex information processing system, which is structured from interconnected segmental processing elements, called neurons. These neurons find the input information from other sources and perform generally a non-linear operation on the result and then give final results as output. ANN works in two ways, first learning and then storing the knowledge in interconnects called weights. The basic structure of artificial neuron is represented in Fig.5. ANN is a simulation tool in MATLAB which can be used to estimate the values on the basis of input parameters, optimum topology and training processes. In feed forward networks, each product of input elements and weights are fed to summing junctions and is summed with bias of neurons as follows $[11,17,18,20]$ :

$$
X=\left(\sum_{i=1}^{n} w_{i j} a_{i}\right)+b_{j}
$$

where, $\mathrm{n}$ is the number of input data $(\mathrm{i}=0,1,2,3 \ldots \mathrm{n})$ and $w_{i j}$ are the interconnecting weights of the input data $a_{i}$, respectively, and $b_{j}$ is the bias for the neuron.

Then this sum $X$ passes through transfer function $F$ which generates an output.

$$
F(X)=u_{j}=F\left(\sum_{i=1}^{n} w_{i j} a_{i}+b_{j}\right)
$$

The most used transfer functions in hidden layer are tansig and $\operatorname{logsig}$. The nonlinear activation function which is widely used is called as sigmoid function whose output lies in between 0 and 1 , and it is given as:

$$
F(X)=\frac{1}{1+e^{-X}}
$$

When at input or output layer, negative values are found, then the tansig transfer function is used, which is written as:

$F(\mathrm{X})=\frac{1-e^{-2 X}}{1+e^{-2 X}}$

The performance index of different training algorithm is represented by mean square error (MSE) and it is formulated as:

$$
M S E=\frac{1}{n} \sum_{i=1}^{n}\left(X_{a, i}-X_{b, i}\right)^{2}
$$

\section{PRESENT ANN MODEL}

In the present work, total 105 sets of experimental data have been collected by conducting experiments for 7 days. The ANN model structured with an input layer, hidden layer and output layer has been shown in Fig.6. In input layer eight parameters, such as mass flow rate of air $(m)$, wind speed $\left(W_{v}\right)$, relative humidity $(R H)$, atmospheric air temperature $\left(T_{a}\right)$, air inlet temperature $\left(T_{i}\right)$, air mean temperature $\left(T_{m}\right)$, plate temperature $\left(T_{p}\right)$ and solar intensity $(I)$, and exergetic efficiency $\left(\eta_{I I}\right)$ as output parameter in output layer, has been selected. The range of input and output parameters are shown in Table 2.

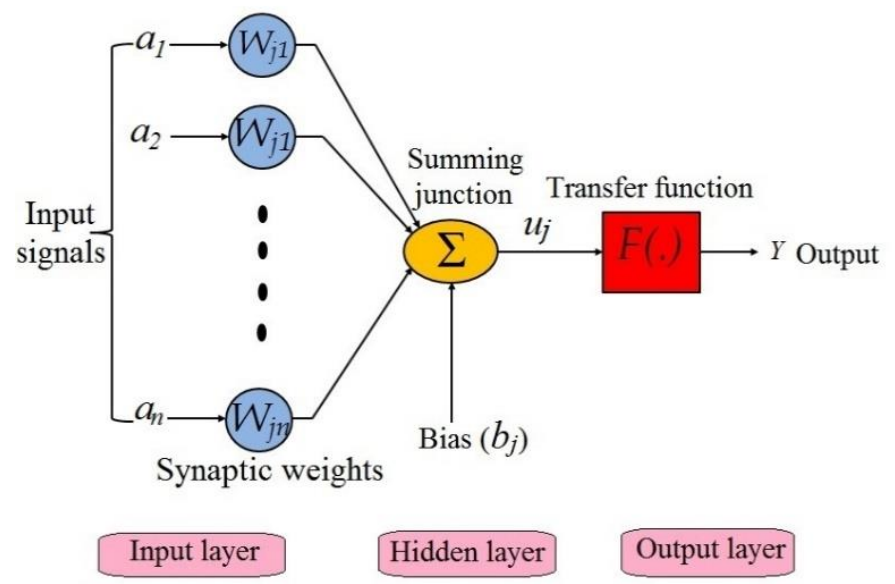

Figure 5. Basic structure of artificial neuron 


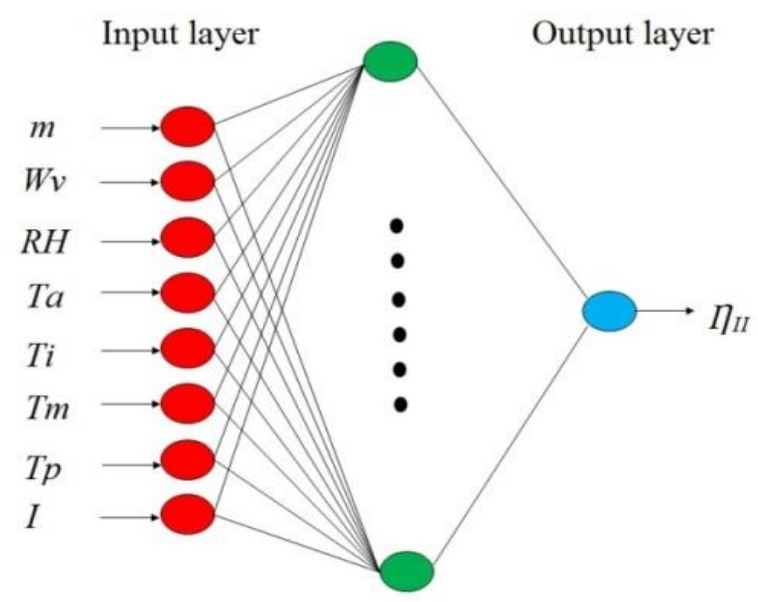

Hidden layer

Figure 6. Proposed ANN model

Table 2. Range of input and output parameters

\begin{tabular}{|c|c|}
\hline Parameters & Range \\
\hline Input parameters & \\
\hline Mass flow rate of air, $m(\mathrm{~kg} / \mathrm{sec})$ & $0.0067-0.0227$ \\
\hline Wind speed, $W_{v}(\mathrm{~m} / \mathrm{sec})$ & $0.38-4.50$ \\
\hline Relative humidity, $R H(\%)$ & $8.04-45.24$ \\
\hline Atmospheric temp., $T_{a}\left({ }^{\circ} \mathrm{C}\right)$ & $19.56-34.77$ \\
\hline Inlet fluid temperature, $T_{i}\left({ }^{\circ} \mathrm{C}\right)$ & $23.11-38.25$ \\
\hline Mean fluid temperature, $T_{m}\left({ }^{\circ} \mathrm{C}\right)$ & $25.625-44.20$ \\
\hline Absorber Plate temp., $T_{p}\left({ }^{\circ} \mathrm{C}\right)$ & $41.35-84.20$ \\
\hline Solar Intensity, $I\left(W / m^{2}\right)$ & $360.85-756.13$ \\
\hline Output parameter & \\
\hline Exergetic efficiency, $\eta_{I I}(\%)$ & $0.4163-1.8941$ \\
\hline
\end{tabular}

\section{RESULTS AND DISCUSSION}

In the present work, MLP model has been used to predict the exergetic efficiency of arc shaped roughened SAH. Total 105 data samples are used in this model which is collected from the experiments. $70 \%$ data were used for training, $15 \%$ data for testing and rest of $15 \%$ data used for validation.

Before developing the ANN structure, the input and output sample data must be normalized between 1 and -1 for accuracy of prediction. In this present work, the following equation is used:

$Y=\frac{Y_{i}-Y_{\min }}{Y_{\max }-Y_{\min }} 2+(-1)$

TRAINLM learning function has been used for training process. After selecting the training function, the adaption learning function was selected as LEARNGDM (Gradient Descent with momentum weight and bias learning function). Tansig transfer function was selected for hidden layer and linear function (purelin) for output layer. The basic steps of ANN simulation flow chart is shown in Fig. 7.

The trial and error method is adopted to select number of neurons in hidden layer. However, some thumb rules are available in the literature for calculation of number of neurons in hidden layer. One of them reported by Ghritlahre and Prasad
[19] to calculate the optimum number of neurons is, as given below:

$H_{n}=\frac{M+N}{2}+\sqrt{T_{n}}$

where $M$ and $N$ are input and output parameters respectively, and $T_{n}$ is number of training data sets.

Each of the MLPNN model has been trained using LM learning algorithm for 50 times by using 10 to 16 neurons in hidden layer from Eq. $(20)[13,20]$ on the basis of trial and error method to find out the optimal neurons. This training algorithm adjusts the weights and biases iteratively to minimize the error between actual and predicted values of ANN model. The performance of MLP model with 10-16 neurons is shown in Table 3. It has been found that LM-14 is optimal neurons in hidden layer on the basis of statistical results. From the Table 3, it has been found that the value of correlation coefficients for training (R1), testing (R2), validation (R3) and all process $(\mathrm{R})$ for 14 neurons are optimal values as compared to other neurons and also found that the value of MSE is lowest. The value of R1, R2, R3 and R has been obtained as $0.99975,0.99422,0.99440$ and 0.99793 respectively, and MSE is 0.000979 . The regression plot of LM14 is shown in Fig. 8. 
Table 3. The statistical error analysis of MLP model with 10-16 neurons in hidden layer

\begin{tabular}{|c|c|c|c|c|c|}
\hline Number of neurons & R1 & R2 & R3 & R & MSE \\
\hline 10 & 0.99753 & 0.96000 & 0.96968 & 0.98950 & 0.004535 \\
\hline 11 & 0.99993 & 0.95265 & 0.97425 & 0.98809 & 0.006642 \\
\hline 12 & 0.99891 & 0.99467 & 0.99392 & 0.99769 & 0.003579 \\
\hline 13 & 0.99971 & 0.99609 & 0.99328 & 0.99785 & 0.000998 \\
\hline $\mathbf{1 4}$ & $\mathbf{0 . 9 9 9 7 5}$ & $\mathbf{0 . 9 9 4 2 2}$ & $\mathbf{0 . 9 9 4 4 0}$ & $\mathbf{0 . 9 9 7 9 3}$ & $\mathbf{0 . 0 0 0 9 7 9}$ \\
\hline 15 & 0.99974 & 0.98727 & 0.97493 & 0.99206 & 0.003968 \\
\hline 16 & 0.99130 & 0.97963 & 0.94674 & 0.98366 & 0.006407 \\
\hline
\end{tabular}

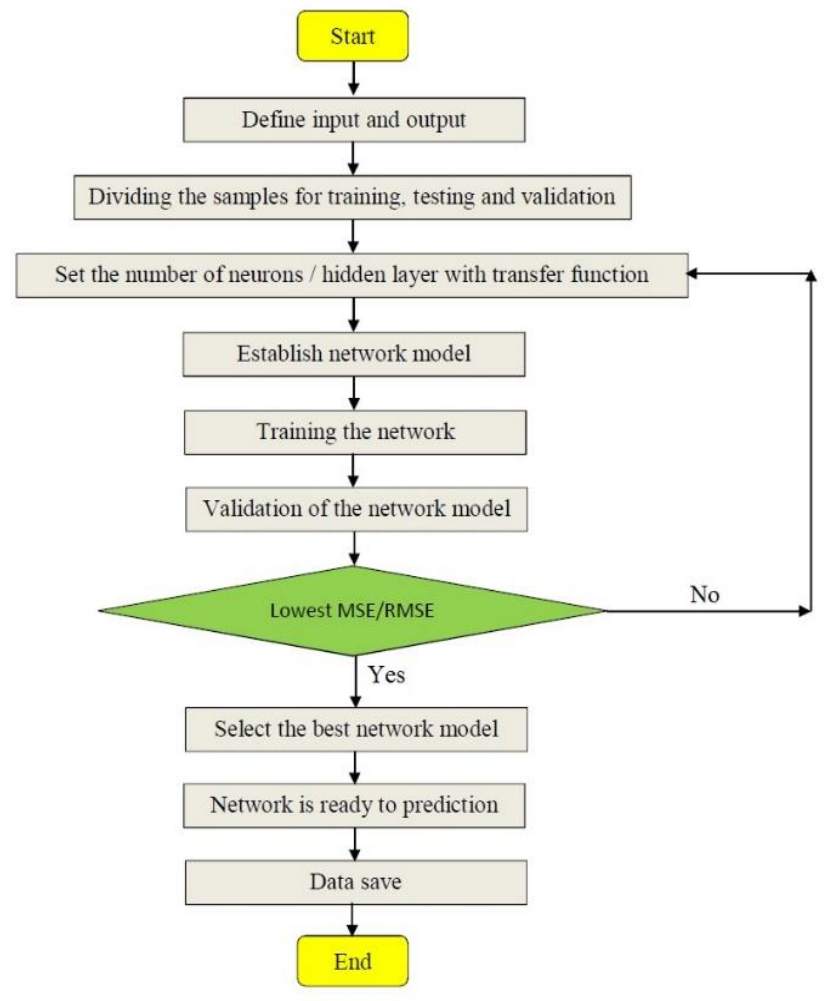

Figure 7. ANN simulation flow chart
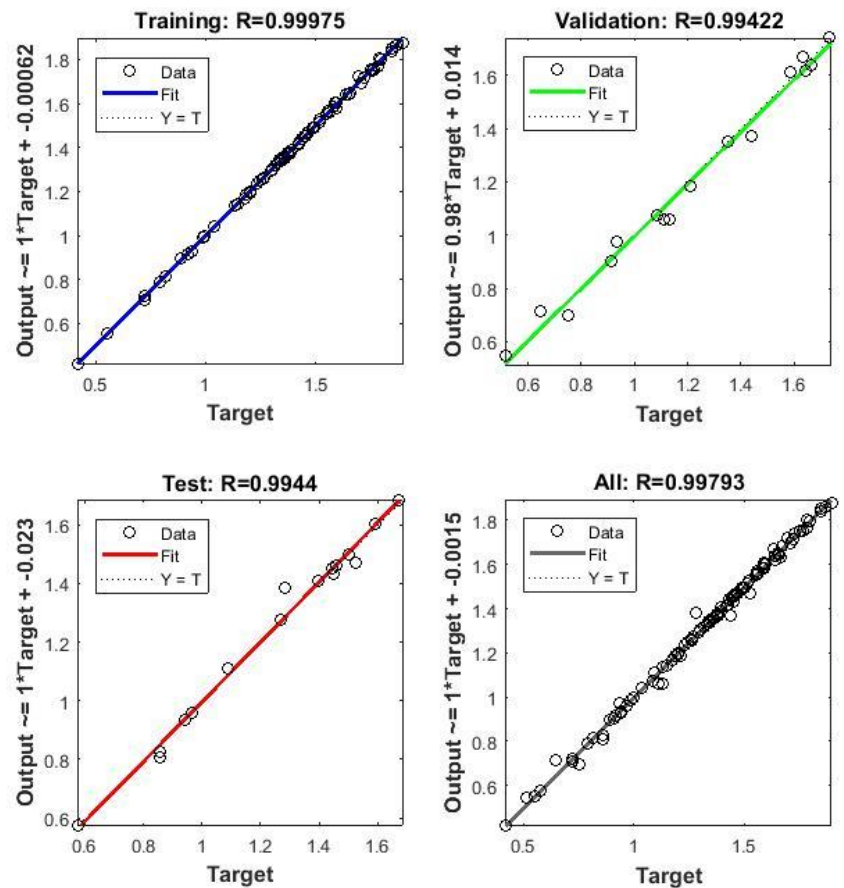

Figure 8. Regression plot of LM-14 


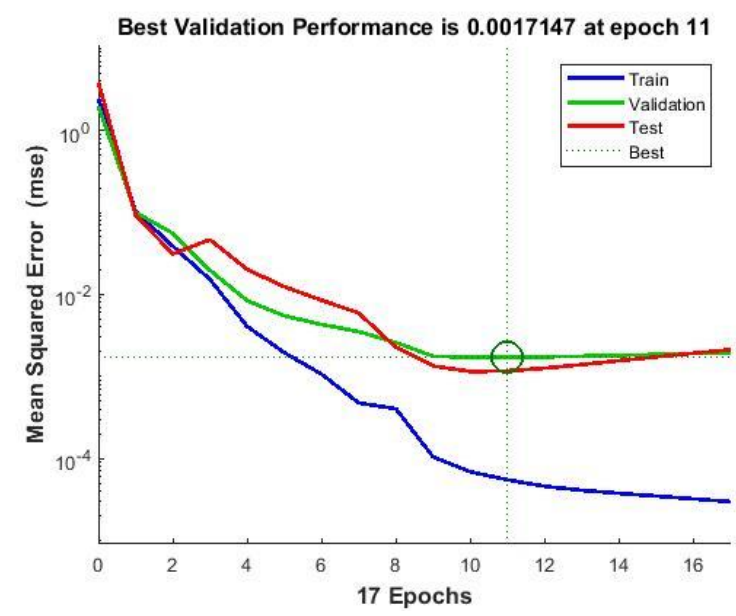

Figure 9. Best performance plot for LM-14
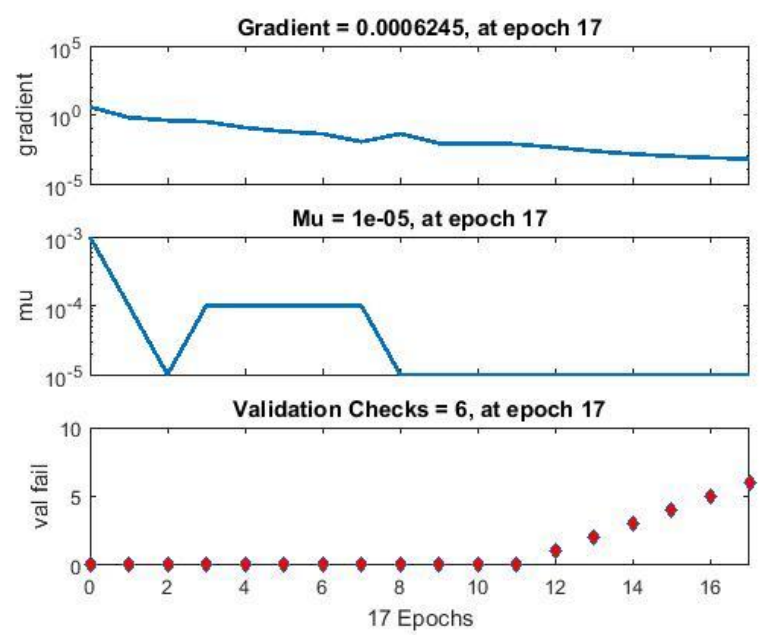

Figure 10. Variation of the gradient error, $\mu$ and validation error

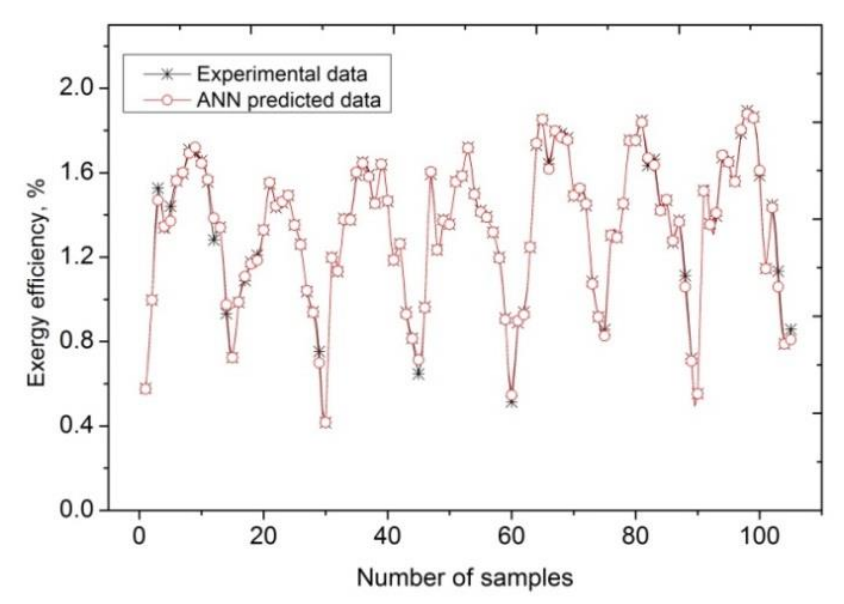

Figure 11. Comparison of experimental and ANN predicted exergy efficiency

The best validation performance (Fig. 9) was found at 11 epoch at which the MSE during validation was found 0.0017147 and the training process stopped at epoch 17 because the minimum gradient error reached, which is examined by Fig. 10. The comparison between experimental and ANN predicted data is shown in Fig. 11 and its individual error bar chart of each samples are shown in Fig. 12.

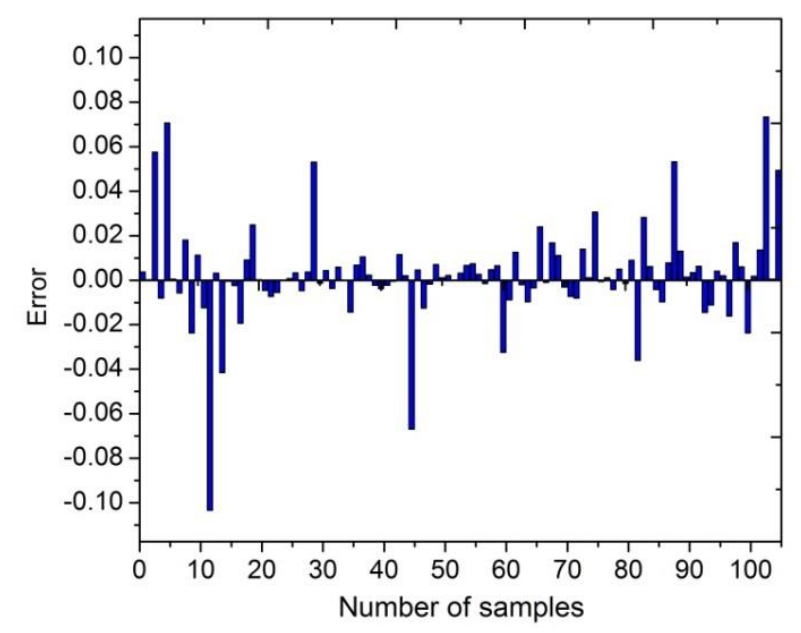

Figure 12. Individuals error of each samples

Table 4. Performance of selected MLP model for prediction of exergy efficiency

\begin{tabular}{|c|c|c|c|}
\hline Parameters & RMSE & COV & $\mathbf{R}^{\mathbf{2}}$ \\
\hline$\eta_{I I}$ & 0.021747 & 1.63766 & 0.99583 \\
\hline
\end{tabular}

Root mean square error:

$R M S E=\sqrt{\frac{1}{n} \sum_{i=1}^{n}\left(X_{a, i}-X_{b, i}\right)^{2}}$

Coefficient of variance:

$\operatorname{COV}=\frac{R M S E}{\frac{1}{n} \sum_{i=1}^{n} X_{b, i}} \times 100$

Coefficient of determination:

$R^{2}=1-\frac{\sum_{i=1}^{n}\left(X_{a, i}-X_{b, i}\right)^{2}}{\sum_{i=1}^{n} X_{b, i}^{2}}$

where $X_{a}$ and $X_{b}$ are actual and predicted data respectively

The performance of predicted data of selected MLP model has been given in Table 4, on the basis of RMSE, COV and $R^{2}$, which are calculated by Eqs. (21), (22) and (23) respectively. From Table 4, it has been found that the value of RMSE and COV are 0.021747 and 1.63766 respectively, which are very less error, and the value of $R^{2}$ is 0.99583 which is near to unity. The above results show that the MLP model with LM-14 successfully predicted the exergetic efficiency of SAH.

\section{CONCLUSIONS}

In the present work experiments were conducted on an arc shape wire rib roughened solar air heater to find the exergy efficiency on various mass flow rate and compered with ANN predicted exergetic efficiency. The measured parameters were solar intensity, wind speed, relative humidity, inlet 
temperature of air, absorbing plate temperature, ambient temperature and mean air temperature. These eight parameters are used in input layer of ANN model. The calculated value of exergetic efficiency is selected as output parameter. The following conclusions have been drawn:

1. By the use of LM learning algorithms, the exergetic performance of solar air heater can successfully be predicted with ANN model.

2. For most optimal topology the numbers of neurons in hidden layer are found to be fourteen (LM-14).

3. The values of RMSE and COV are obtained as 0.021747 and 1.63766 respectively, which are very low as required for accurate prediction.

4. The value of coefficient of determination $\left(R^{2}\right)$ of predicted data is 0.99583 , which shows the accuracy of the MLP model.

The above conclusions shows that the MLP neural network is appropriate model to successfully the exergetic efficiency of arc shaped wire roughened solar air heater.

\section{ACKNOWLEDGMENT}

The Authors are very thankful to National Institute of Technology, Jamshedpur, India for providing all the facilities to carry out the research work.

\section{REFERENCES}

[1] Duffie JA, Beckman WA. (1991). Solar Engineering of Thermal Processes. second ed.,Wiley Publication, New York.

[2] Garg HP, Prakash J. (2000). Solar Energy Fundamentals and Applications. First ed., Tata McGraw-Hill, New Delhi.

[3] Prasad BN, Behura AK, Prasad L. (2014). Fluid flow and heat transfer analysis for heat transfer enhancement in three sided artificially roughened solar air heater. Sol. Energy 105: 27-35. https://doi.org/10.1016/j.solener.2014.03.027

[4] Sharma SK, Kalamkar VR. (2015). Thermo-hydraulic performance analysis of solar air heaters having artificial roughness - A review. Renewable and Sustainable Energy Reviews 41: 413-435. https://doi.org/10.1016/j.rser.2014.08.051

[5] Sahu MK, Prasad RK. (2016). A review of the thermal and thermo hydraulic performance of solar air heater with roughened absorber plate. Journal of Enhanced Heat Transfer 23(1): 47-89. https://doi.org/10.1615/JEnhHeatTransf.2017015624

[6] Sahu MK, Prasad RK. (2017). Thermo hydraulic performance analysis of an arc shape wire roughened solar air heater. Renewable Energy 108: 598-614. https://doi.org/10.1016/j.renene.2017.02.075

[7] Cengel YA, Boles MA. (2006). Thermodynamics: An engineering approach. 5th ed. New York: McGraw-Hill. https://www.mheducation.co.in

[8] Alta D, Bilgili E, Ertekin C, Yaldiz O. (2010). Experimental investigation of three different solar air heaters: Energy and exergy analyses. Applied Energy 87: 2953-2973.

https://doi.org/10.1016/j.apenergy.2010.04.016

[9] Lalji MK, Sarvaiya RM, Bhagoriya JL. (2012). Exergy evaluation of packed bed solar air heater. Renewable and Sustainable Energy Reviews 16: 6262-6267. https://doi.org/10.1016/j.rser.2012.04.024

[10] Sahu MK, Prasad RK. (2016). Exergy based performance evaluation of solar air heater with arc-shaped wire roughened absorber plate. Renewable Energy 96: 233243. https://doi.org/10.1016/j.renene.2016.04.083

[11] Haykin S. (1994). Neural Networks: A Comprehensive Foundation. New Jersey: Prentice- Hall, New Jersey.

[12] Kalogirou SA. (2000). Applications of artificial neuralnetworks for energy systems. Applied Energy 67(1-2): 17-35. https://doi.org/10.1016/S0306-2619(00)00005-2

[13] Kalogirou SA. (2006). Prediction of flat-plate collector performance parameters using artificial neural networks. Solar Energy 80: 248-259. https://doi.org/10.1016/j.solener.2005.03.003

[14] Sozen A, Menlik T, Unvar S. (2008). Determination of efficiency of flat-plate solar collectors using neural network approach. Expert Syst. Appl. 35(4): 1533-1539. https://doi.org/10.1016/j.eswa.2007.08.080

[15] Caner M, Gedik E, Kecebas A. (2011). Investigation on thermal performance calculation of two type solar air collectors using artificial neural network. Expert Syst. Appl. 38(3): 1668-1674. https://doi.org/10.1016/j.eswa.2010.07.090

[16] Benli H. (2013). Determination of thermal performance calculation of two different types solar air collectors with the use of artificial neural networks. Int. J. of Heat and Mass Transfer 60: 1-7. https://doi.org/10.1016/j.ijheatmasstransfer.2012.12.042

[17] Ghritlahre HK, Prasad RK. (2017). Prediction of thermal performance of unidirectional flow porous bed solar air heater with optimal training function using Artificial Neural Network. Energy Procedia 109: 369-376. https://doi.org/10.1016/j.egypro.2017.03.033

[18] Ghritlahre HK, Prasad RK. (2017). Energetic and exergetic performance prediction of roughened solar air heater using artificial neural network. Ciência e Técnica Vitivinícola 32(11): 2-24. http://ciencia-etecnica.org/view.php? $\mathrm{v}=32 \& \mathrm{i}=11$

[19] Ghritlahre HK, Prasad RK. (2018). Application of ANN technique to predict the performance of solar collector systems - A review. Renewable and Sustainable Energy Reviews 84: 75-88. https://doi.org/10.1016/j.rser.2018.01.001

[20] Ghritlahre HK, Prasad RK. (2018). Exergetic performance prediction of roughened solar air heater using artificial neural network. Strojniški vestnik Journal of Mechanical Engineering 64(3): 195-206. http://dx.doi.org/10.5545/sv-jme.2017.4575

[21] Ghritlahre HK, Prasad RK. (2018). Development of optimal ANN model to estimate the thermal performance of roughened solar air heater using two different learning algorithms. Annals of Data Science 5(3): 453-467. https://doi.org/10.1007/s40745-018-0146-3

[22] Ghritlahre HK, Prasad RK. (2018). Exergetic performance prediction of solar air heater using MLP, GRNN and RBF models of artificial neural network technique. Journal of Environmental Management 223: 566-575. https://doi.org/10.1016/j.jenvman.2018.06.033

[23] Ghritlahre HK, Prasad RK. (2018). Investigation on heat transfer characteristics of roughened solar air heater using ANN technique. International Journal of Heat and Technology 36(1):

102-110. 
https://doi.org/10.18280/ijht.360114

[24] Ghritlahre HK. (2018). Development of feed-forward back-propagation neural model to predict the energy and exergy analysis of solar air heater. Trends in Renewable Energy 4(2):

213-235. https://doi.org/10.17737/tre.2018.4.2.0078

[25] Ghritlahre HK, Prasad RK. (2018). Prediction of heat transfer of two different types of roughened solar air heater using Artificial Neural Network technique. Thermal Science and Engineering Progress. https://doi.org/10.1016/j.tsep.2018.08.014

[26] Ghritlahre HK, Prasad RK. (2018). Investigation of thermal performance of unidirectional flow porous bed solar air heater using MLP, GRNN, and RBF models of ANN technique. Thermal Science and Engineering Progress 6: 226-235. https://doi.org/10.1016/j.tsep.2018.04.006

[27] Wang RZ, Liu PD, Qian YM, Zhan J. (2017). Application and design of split solar water heater with conversion of solar energy into thermal energy through chemical methods. Chemical Engineering Transactions 62: 397-402. https://doi.org/10.3303/CET1762067

[28] Jumari NF, Yusof KM. (2017). Comparison of melt flow index of propylene polymerization in loop reactors using first principles and artificial neural network models. Chemical Engineering Transactions 56: 163-168. https://doi.org/10.3303/CET1756028

\section{NOMENCLATURE}

$A_{C} \quad$ Area of collector absorber surface, $\mathrm{m}^{2}$

\section{ANN Artificial Neural Network}

$a_{i} \quad$ input variables

$b_{j} \quad$ bias

$C_{p f} \quad$ specific heat of air, $\mathrm{J} \mathrm{kg}^{-1} \cdot \mathrm{K}^{-1}$

$\mathrm{COV}$ coefficient of variance

$e \quad$ roughness height, $\mathrm{mm}$

$e / D \quad$ relative roughness height

$\dot{E}$ energy rate, W

Ex exergy rate, $\mathrm{W}$

Ex $x_{\text {dest }}$ rate of irreversibility, W

$h \quad$ enthalpy, $\mathrm{J}_{\mathrm{kg}}{ }^{-1}$

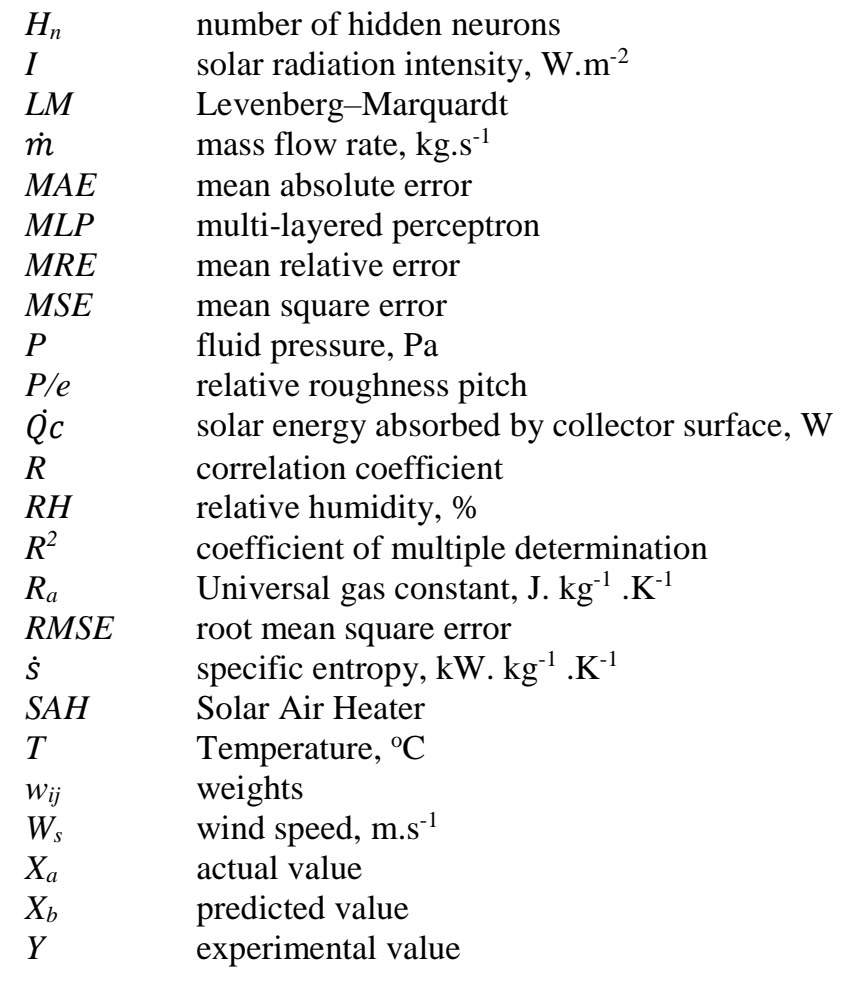

\section{Greek letters}

$\begin{array}{ll}\alpha & \text { angle of attack, degree } \\ \eta_{I I} & \text { exergy efficiency, \% } \\ \psi & \text { specific exergy, }{\mathrm{J} . \mathrm{kg}^{-1}}^{-1}\end{array}$

\section{Subscripts}

$\begin{array}{ll}a & \text { ambient air } \\ c & \text { collector } \\ f i & \text { inlet air } \\ f o & \text { outlet air } \\ m & \text { mean } \\ g e n & \text { generation } \\ i & \text { inlet } \\ \text { min } & \text { minimum } \\ \text { max } & \text { maximum } \\ o & \text { outlet } \\ p & \text { plate } \\ s & \text { sun }\end{array}$

